Vicente Mengod

\title{
Sobre dos libros de Latorre
}

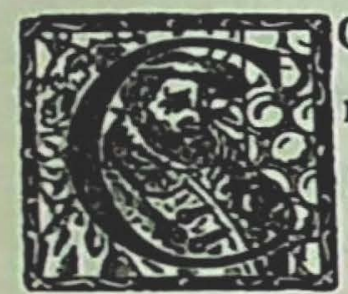

ON frecuencia, al enfocar la obra de un escritor, interesa citar sus obras fundamentales. He ahí un procedimiento para fijar normas de valoración. Sin embargo, no me guía ese propósito al enunciar unas divagaciones en torno a dos obras de Mariano Latorre. Pretendo, más bien, exponer mis reacciones críticas, decir de qué forma actuaron en mi sensibilidad de lector los libros titulados Mapu y Viento de Mallines.

Mapu queda parcialmente situado en el tipo de literatura llamada "criollista", en cuanto se ciñe a la preocupación de captar e interpretar la realidad vital de indios y mestizos, según un criterio poético de trabajosa estilización literaria.

Collanmapu, nombre eufónico de araucana significación, es el dilatado dominio de tierra, en el Chile austral, en donde se prenden los relatos.

Se inicia el libro con una exposición de los factores que contribuyeron a confundir la ruca y el rancho, transformación que fué posible por ese trabajar del tiempo que empuja y dispara a los hombres y organizaciones sociales en una pendiente de adaptación y de singular progreso.

Los capítulos del libro, distribuídos según un alternado criterio de dinamicidad y estatismo, repiten y exaltan algunos motivos en los que únicamente puede vincularse la unidad. El tema del indio 
indolente, de cuchillo fácil y presto a carnear la mansa res o el caballo de nervio, sin que el concepto de propiedad le imponga trabas, se repite en varias ocasiones, así como las contiendas que sólo dirime el brillo de una hoja acerada. Es la ley del más fuerte y del que sabe nutrir su fuerza con la astucia.

El hombre del Mapu, cruce de indígenas y expoliadores, hombre de ojos claros y tez rosada o angulosa, insinuada en pómulos de bronce, sabe del espíritu sentencioso y grave, esa manera de ser que recuerda la sabiduría del refranero español. $\mathrm{Y}$ así, haciendo uso y alarde de su natural y rústica biblia de colono, su actuación se conforma a viejas normas: "Cuando el sol se dentra, el pión se sienta".

Son interesantes en extremo los tipos humanos que viven o arrastran su existencia en las páginas de este libro de Mariano Latorre, pero estimo que los personajes de mayor significación no son los inquilinos de moral dudosa, ni los araucanos catadores del muday, que embriaga y adormece, empujando la mente al desvarío, ni tampoco las hembras indígenas de pecho alzado y manos que ofrendan el ulpo en la callana, sino que, más bien, lo son la tierra y los animales, la rama de los árboles en donde la savia se hace abundosa, y el rayo de luz que taladra la quietud y silencio de la selva. He ahí unos seres que cumplen el raro prodigio de hablar a nuestra sensibilidad.

Cuando Mariano Latorre hace discurrir a sus personajes y les ordena sus palabras e incluso sus gestos, la naturalidad cede su paso. En cambio, cuando cesa el diálogo y la descripción cobra impulso, diríase que las imágenes, concreciones de originalidad y precisión, pugnan por aglomerarse en su pluma, y sólo se desplazan para ceder el paso a nuevos hallazgos del mejor cuño impresionista.

En la selva, "el silencio se posa como un pájaro cansado". Y en el manzanar que cubre el llano hasta el río, "las manzanas de oro son pechos de jilgueros detenidos entre las ramas". 
El rumor de las luciérnagas, con su estrella de luz, pone en la quietud y foscor de la noche una vibración poética, breve y densa. Los rebaños de ovejas andariegas y de recentales, tal vez de blancura viva y donosa, reclaman a sus dueños, pastor adulto o adolescente zagal, diestros en el volteo de la onda, en la que se incuba el certero disparo. Y la colmena tendida en la axila de un pellín, roble chileno duro e incorruptible, entrega su calor hogareño a las abejas, "lunares negros o claros, rubios de sol o azules de sombra vegetal". Trabajadoras que, con diligencia de comadres, faenan para beneficio y poesía de los hombres.

El puelche, viento "que saltando los cerros nevados galopa sobre los bosques y valles de Chile" es uno de los personajes que mejor dicen su voz. La chispa anónima prende en la noche de la selva el sortilegio de sus lenguas de fuego, que se agazapan y huyen apenas llegada "la penumbra incolora del amanecer". Y entonces, el abrasado verdor de los árboles sugiere la imagen de un templo en ruinas, pero aún seguirán zumbando los moscardones "pedacitos de selva, gordos y grávidos como los cóguiles que el estío llena de jugosos granos obscuros".

La tragedia del viejo toro Pampa, todavía joven, en su prodigiosa virilidad, y el epitalamio de las bestias en celo, son objetivos estéticos plenamente logrados. En los distintos apartados en que se prende el relato se hallan coordinados, en feliz y justa medida, la emoción y lo pintoresco, el lirismo y el humor.

$\mathrm{Si}$ bien es cierto que una de las necesidades del espíritu es la de clasificar y definir, reduciendo, en cuanto es posible, lo disperso a unidad armónica, decir escuetamente que Mapu se encuadra totalmente en el tipo de literatura criollista sería una precipitada afirmación. Y además, poco adecuada para resumir sus méritos.

Mapu podría ser calificada de obra costumbrista, si nos fijásemos, tan sólo, en los motivos que le sirven de telón de fondo. Pero he ahí que la obra abunda en elementos subjetivos, de tal fuerza, que muchas veces ahogan y difuminan en su vuelo interpretativo la preciada realidad. Con razón se ha dicho que "la verdad del arte de 
Mariano Latorre es siempre superior a la verdad de la vida". Y en estas condiciones, el costumbrismo, por mucho que sugiera, st verá amputado de la necesaria exactitud.

En esta obra, Mariano Latorre exhibe sus condiciones de poeta, de erudito conocedor de las escondidas técnicas del idioma, y condicionado por una sólida cultura literaria que le impedía ser objetivo al observar el mundo circundante.

Mapu es una visión poética de hombres y de paisajes. Los temas, concretos y objetivos en apariencia, se diluyen en innúmeros meandros subjetivos. El incesante afán de poetizar desarticula a los personajes. Las frecuentes onomatopeyas confieren a esta prosa un bello ritmo musical. Y como resultado de todo ello, los indios y los criollos se convierten en personajes que alguien diría irreales.

Quizás en esta obra, Mariano Latorre consiguió una de sus más altas cimas estilísticas, si bien en perjuicio de la realidad. He ahí una de las facetas poéticas de un criollismo entrañable y soñado.

\section{营 * * *}

En Viento de Mallines, como núcleo vital se yergue el hombre inmerso en un paisaje. Los protagonistas realizan sus vidas, de tipo reducido si cabe, pero valorizadas hasta su plenitud estética y humana mediante el ritornelo de esos matices del ambiente que, repetidos, llegan a convertirse en soplo anímico.

Viento de Mallines, título del primero de los relatos, sirve para rotular el libro. Mariano Latorre utiliza, como nervio de sus ficciones, alguna de las viejas consejas. La acción novelesca, ligeramente esbozada, discurre entre los límites de pretéritas y actuales supersticiones. Y como expresión humorística se inserta en ellas el estudiado contraste de la nota cómica, maliciosa, prolongada en frases y hechos de gañanes de elemental psicología.

En el desarrollo de temas como el de "la yunta robada", se colocan, en primer plano, los rasgos sociológicos propios de toda colectividad. El pueblo se asocia al delincuente hasta el extremo de crear síntomas de inquietud personal en quienes pretenden hacerse 
representantes activos de la autoridad. Toda la fábula se desgrana en torno a una persona cuyo natural reflejo nos sugiere la figura de los grandes rastreadores, ya exaltados en bellas páginas de Sarmiento.

El deseo de eternizar lo estático tiene su realización en el relato de los cóndores, viejos dueños de los riscos cordilleranos y de los agrestes y desolados parajes. Otras veces, una carreta en la montaña, una mujer desconocida y la llama del amor que se prende en la cintura son el tema de una noche de amor. Unas ovejas perdidas le inspiran a Mariano Latorre el recuento de los conceptos de propiedad. Ovejas que se esfuman, refundidas en tragedia, mientras que el alma de un viejo llama desde las profundidades de un barranco, hundido en lejanías de nieve.

En esta obra, como es habitual en la producción de Latorre, el paisaje, está vívido, según la técnica del miniaturista. He ahí un procedimiento de animar y situar en primer plano los más insospechados detalles. Precisamente esa atención al detalle, a lo mínimo, crea en el autor una morosidad descriptiva que muchas veces le impide sostener un clima dinámico para que sus personajes, casi siempre simbólicos y por excepción humanamente individuales, le digan al lector sus vibraciones y sus inquietudes.

Se observa también que en ciertas ocasiones el protagonista criollo, a pesar de su indiscutible personalidad, sólo adquiere categoría en los relatos, cuando se le sitúa en parangón con gentes de otras latitudes. Parece ser que Mariano Latorre, para insuflar a sus personajes una personalidad típica, a veces al borde de la pulverización por exceso de poesía, recurre al procedimiento de hacerles hablar usando algunos de los giros idiomáticos que le son amables. Pero la personalidad del autor, eminentemente poética y subjetiva, difumina este recurso. $\mathrm{Y}$ así, entre las banderolas de las expresiones criollas, surge el lenguaje castellano, musical, exacto, alumbrado con esfuerzo, poniendo en juego pasión y cerebro.

Viento de Mallines es signo de uno de los mejores matices del arte de Mariano Latorre. La prosa bien trabajada llega a concreciones de belleza, en períodos circunstanciados o en frases rápidas, pro- 
cedimientos ambos que requieren cuidadosa atención y capacidad emocional para captar el destello minúsculo, la vibración escondida que, en virtud de un raro prodigio, se hace realidad en una brisa, en un gesto o en un silencio prolongado.

Sin duda, valen en este libro la insinuación del problema psicológico, el tornasol de bellas metáforas y la visión crepuscular de hombres y de paisajes.

En varias de sus páginas las frases cabalgan de acuerdo con un ritmo, con una musicalidad, que alguien diría producto de meticulosos ejercicios gramaticales. Pero este ritmo, aunque deliberado, no insiste en conseguir dilatadas escalas métricas. Es frecuente, en Mariano Latorre el uso de simbolismos, de metáforas fónicas, que van más lejos de la habitual y sencilla onomatopeya.

Los temas del folklore llegan a su obra como literatura artística, con un paramento lírico de gran alcurnia. Con frecuencia, el dato concreto se mezcla a la reacción puramente sentimental. De ahí su tendencia a idealizar los hombres, a dibujar los paisajes.

Me atrevería a decir que Latorre ha sido un escritor barroco, ya que los contornos de sus personajes quedan como diluídos en el paisaje circundante. Su minuciosidad descriptiva produce aquella su habitual impresión barroca de los tipos humanos.

Muchas veces, la crítica ha querido penetrar en las obras de Mariano Latorre, acudiendo al recurso de fijar su analogía con determinados escritores extranjeros y nacionales. $Y$ este procedimiento le ha impedido ver y aquilatar los valores que de manera natural brotaban de su obra de arte.

Ahora bien, mis divagaciones críticas son psicologistas, pues mi atención se ha centrado en las reacciones, en las vibraciones emocionales habidas en $\mathrm{mi}$ yo privado, sin acudir a puntos de referencia docta y bibliográfica.

Se ha dicho que la valoración de una obra es algo así como la toma de conciencia de cualidades y de relaciones estéticas valiosas, pero que están presentes en una obra de creación literaria. Es exacto que los valores están en potencia en las estructuras literarias. Quizás 
sólo los advierten los lectores sencillos, dispuestos a dejarse mecer por la emoción. Tal vez, entonces, esos valores se entregan incondicionalmente.

Sin duda hay un juicio de sensibilidad. Y éste es el mío, el que me ha movido a recordar la impresión que me produjeron dos libros de Mariano Latorre, hace algunos años, cuando por primera vez tomé contacto con las obras de un profesor eximio de castellano, que hacía literatura para encontrar a su pueblo, para tratar de hallarse a sí mismo.

Es muy posible que una deformación de tipo didáctico obligara al escritor a recargar sus frases, a nutrirlas de preciosismos gramaticales, llegando a formular y resolver enrevesados problemas de técnica literaria. Por esta razón, varios de sus diálogos son de una inteligente falsedad, extienden su mensaje mucho más allá de los términos y dominios de una conversación habitual, posible en los ámbitos criollos.

Por excepción cultiva el interés de la lengua hablada, del llano decir, sin arreglos alambicados.

Sabido es que existe una diferencia entre esa lengua hablada y la lengua escrita. La primera usa principalmente el recurso alusivo. Hablando no se usan los vínculos gramaticales que encajonan el pensamiento y comunican a la frase el aspecto concienzudo de un silogismo. La lengua hablada es manejable, ágil, señala la unión mutua de las proposiciones por medio de indicaciones breves y sencillas. La entonación tiene gran importancia, indica la relación de dos frases inmediatas oponiéndolas.

En otros escritores costumbristas se da este milagro del lenguaje hablado, una sencillez que se aproxima al decir espontáneo, como resultado de una emoción viva, tal vez de menos quilates estilísticos.

Entiendo que es necesario leer despacio la prosa de Latorre, porque sus pensamientos están encuadrados en las reglas estrictas del lenguaje gramatical.

Lo que en Mariano Latorre se nos da resuelto, en otros cuentistas, de menos categoría, no pasa de ser una incitación. El primero 
llega a cincelar las metáforas. Los segundos se quedan en los umbrales, nos hacen pensar en la posibilidad, en los términos de una metáfora impura, de una imagen sin culminación literaria.

Los investigadores de los procesos lingüísticos dicen que es falso considerar el lenguaje como una entidad ideal, susceptible de evolucionar independientemente de los hombres, como si persiguiese fines propios. Por el contrario, el lenguaje no existe fuera de quienes lo piensan y lo hablan. Se sumerge en las profundidades de la conciencia individual. Sólo de allí toma la fuerza para formarse en la boca de los hombres. Por esta razón, cuando se le reviste de excesivas galas retóricas se produce el desequilibrio, las conversaciones son falsas, la personalidad del escritor ahoga, por desgracia, el natural impulso de sus personajes.

Para la valoración exacta de Mariano Latorre urge la tarea de aquilatar la humanidad de sus tipos novelescos. Es necesario puntualizar los límites de su calidad y perfección estilística. Sin duda, esta labor minuciosa nos entregará la imagen real de un artista que laboraba sus obras con la paciencia de un miniaturista, volcándose entero en cada página, haciendo de su profesión de escritor un armonioso problema de dignidad estética. 